\title{
HOW ABIOTIC FACTORS AFFECT THE DISTRIBUTION OF TWO SPECIES OF TROPICAL PREDACEOUS AQUATIC BUGS (FAMILY: NAUCORIDAE) ${ }^{1}$
}

\author{
R. JEAN STOUT ${ }^{2}$ \\ Division of Biological Sciences, University of Michigan, Ann Arbor, Michigan 48109 USA
}

\begin{abstract}
Heavy runoff from watersheds affects lowland streams in two general ways. Either a stream experiences spates (increased forward velocity and scouring of stream bottoms) or it becomes inundated by waters from larger rivers, causing the stream to be backflooded. This study shows how these features affect the abundances and distributions of two Costa Rican species of stream-inhabiting predaceous waterbugs, Limnocoris insularis Champion and Cryphocricos latus Usinger (Naucoridae).

Backflooding in the Sura was found to have no subsequent effect on the abundances or distribution of either species. But in the Sabalo, which spates, nymphal populations of $L$. insularis significantly decrease after a spate because of loss of numbers and loss of previous habitat. During severe spates, adults of both species can be washed out, causing abundances to remain low for several months to periods $>1 \mathrm{yr}$.

Abundances of nymphs and adults of $C$. latus are associated with fast current speeds, large rocks, and coarse-grained pebbles. These sorts of habitats are found in both streams. Even though C. latus is more common in the Sabalo than is $L$. insularis, abundances of adults of the former species fluctuate more in the stream that spates than in the stream that does not, owing both to a high washout rate and to a slow recolonization rate. The basic pattern of distribution is explained by the difference between the flooding characteristics of the two streams.

Key words: backflooding; Costa Rica; Cryphocricos latus; Limnocoris insularis; spates; streams; substrata; tropical; velocity.
\end{abstract}

\section{INTRODUCTION}

In streams many potential controlling factors can be measured quantitatively. The abundances of streamdwelling insects have often been found to be correlated with substrata type and with velocity (Cummins 1964, Edington 1965, 1968, Cummins and Lauff 1969, Egglishaw 1969, Hynes 1970, Reice 1980). Naucorids, predaceous hemipterans, are little known although they dominate tropical streams and probably greatly influence other biota. The purpose of this study was to determine how two types of stream hydrologies affected the abundances and distributions of two naucorid species, Limnocoris insularis Chapman and Cryphocricos latus Usinger.

Two contrasting Costa Rican stream sites where both species were found were studied; the Sabalo and the Sura. These have differences such as maximum velocities and direction of flow during floods, frequency of floods, substrata type, and mobility of substrata during floods.

The Sabalo has a higher gradient and drains a larger area than does the Sura. The main river, the Puerto Viejo, receives runoff from mountainous areas to the south and this can fill the river up to $12 \mathrm{~m}$ above normal depth by the time it flows past the Sabalo and El

\footnotetext{
${ }^{1}$ Manuscript received 23 August 1979; revised 27 September 1980; accepted 14 October 1980.

${ }^{2}$ Present address: Department of Zoology, Michigan State University, East Lansing, Michigan 48824 USA.
}

Sura streams. The Sabalo also receives water from an extensive watershed. Both the Sabalo and the Puerto Viejo experience spates. Forward velocity increases, water becomes turbid, and stream bottoms are eroded. However, the Sura is only indirectly affected by rainfall to the south. It drains a small watershed, so rather than filling from its watershed, most of the increased volume enters its mouth from the swollen Puerto Viejo River. Water depth can increase up to $9 \mathrm{~m}$, and the direction of flow often reverses, causing water velocities to be reduced (maximum backflow velocity: 62 $\mathrm{cm} / \mathrm{s}$; maximum forward velocity: $130 \mathrm{~cm} / \mathrm{s}$ ), and at times the Sura becomes a virtual lake as far back as $500 \mathrm{~m}$ from its mouth. Quiet water can persist from a few minutes to $2 \mathrm{~h}$. The Sura never spates. Although water is turbid during backflooding, only fine sediments are moved.

Floods occur frequently in the wet season (June to September) but floods can also occur at other times of the year. Some of the heaviest floods have been recorded in December during 'temporales' when rains persist from hours to days. Streams that spate erode adjacent land; in fact, the Sabalo changed its course near its mouth between 1978 and 1979. Flood control measures are necessary for these sorts of lowland streams as land usage intensifies; however, streams that are backflooded maintain their stream banks. The most stable alluvial soils, in fact, are adjacent to these streams.

The differential responses to rains by lowland 
TABLE 1. Statistical comparison of animal abundances in the Sura and Sabalo ( $t$ test). Means represent the average over the indicated stations, of the number of animals taken at each microsite (three handscreen samples per station).

\begin{tabular}{|c|c|c|c|c|c|c|c|c|c|}
\hline \multirow{3}{*}{$\begin{array}{l}\text { Species and stage } \\
\text { Stations }\end{array}$} & \multicolumn{9}{|c|}{ Streams and stations } \\
\hline & \multicolumn{3}{|c|}{$\begin{array}{l}\text { A. Sura }(1-3,5) \\
\text { B. Sabalo }(1-6)\end{array}$} & \multicolumn{3}{|c|}{$\begin{array}{l}\text { A. Sura (1-3) } \\
\text { B. Sura (5-7) }\end{array}$} & \multicolumn{3}{|c|}{$\begin{array}{l}\text { A. Sabalo (1-4) } \\
\text { B. Sabalo }(7-10)\end{array}$} \\
\hline & $\bar{x}$ & $t$ & $n$ & $\bar{x}$ & $t$ & $n$ & $\overline{\boldsymbol{x}}$ & $t$ & $n$ \\
\hline L. insularis, adults & & & & & & & & & \\
\hline $\begin{array}{l}\text { Stations (A) } \\
\text { Stations (B) }\end{array}$ & $\begin{array}{r}15.9 \\
3.0\end{array}$ & $5.1 * * *$ & $\begin{array}{l}18 \\
18\end{array}$ & $\begin{array}{l}13.0 \\
17.0\end{array}$ & -0.9 & $\begin{array}{l}9 \\
9\end{array}$ & $\begin{array}{l}7.6 \\
1.0\end{array}$ & $4.8^{* * *}$ & $\begin{array}{l}12 \\
12\end{array}$ \\
\hline $\begin{array}{l}\text { L. insularis, nympl } \\
\text { Stations (A) } \\
\text { Stations (B) }\end{array}$ & $\begin{array}{l}8.8 \\
1.5\end{array}$ & $5.1^{* * *}$ & $\begin{array}{l}18 \\
18\end{array}$ & $\begin{array}{l}9.0 \\
6.0\end{array}$ & 1.2 & $\begin{array}{l}9 \\
9\end{array}$ & $\begin{array}{l}2.1 \\
0.3\end{array}$ & $1.8 \dagger$ & $\begin{array}{l}12 \\
12\end{array}$ \\
\hline $\begin{array}{c}\text { C. latus, adults } \\
\text { Stations (A) } \\
\text { Stations (B) }\end{array}$ & $\begin{array}{l}3.0 \\
2.7\end{array}$ & 0.3 & $\begin{array}{l}18 \\
18\end{array}$ & $\begin{array}{l}2.3 \\
4.0\end{array}$ & -1.7 & $\begin{array}{l}9 \\
9\end{array}$ & $\begin{array}{l}0.5 \\
4.0\end{array}$ & $-5.0^{* * *}$ & $\begin{array}{l}12 \\
12\end{array}$ \\
\hline $\begin{array}{l}\text { C. latus, nymphs } \\
\text { Stations (A) } \\
\text { Stations (B) }\end{array}$ & $\begin{array}{l}1.8 \\
0.7\end{array}$ & $3.7^{* *}$ & $\begin{array}{l}18 \\
18\end{array}$ & $\begin{array}{l}1.5 \\
2.5\end{array}$ & $-2.1^{*}$ & $\begin{array}{l}9 \\
9\end{array}$ & $\begin{array}{l}0.4 \\
1.0\end{array}$ & $-3.3^{* *}$ & $\begin{array}{l}12 \\
12\end{array}$ \\
\hline
\end{tabular}

streams have potential effects on stream communities. Whether or not stream bottoms are scoured certainly affects abundances of naucorids. Secondarily, movement patterns of the animals are affected by direction and velocity of flow.

The study site is located $2 \mathrm{~km}$ southwest of the town of Puerto Viejo in Heredia Province, $10^{\circ} 27^{\prime} \mathrm{N}, 84^{\circ} 0^{\prime} \mathrm{W}$. The Finca (owned and operated by the Organization for Tropical Studies) ranges in elevation from 50 to $150 \mathrm{~m}$ above sea level and receives an average annual rainfall of $3900 \mathrm{~mm}$. It is drained by three streams, all of which empty into the Puerto Viejo River (stream order number 6).

\section{Materials AND Methods}

Ten stations were established in streams and were from 10 to $15 \mathrm{~m}$ apart, except for an hiatus of $1700 \mathrm{~m}$ between stations 1-5 and 6-10. (Station 1 is closest to the Puerto Viejo.) At each station, three microsites were chosen: left, center, and right.

Water depths, velocities, and dissolved oxygen were recorded at all microsites. Temperature variation was recorded with Taylor maximum-minimum thermometers. Maximum flow rates were taken directly with a General Oceanics Digital Flowmeter, Model 2030, and were also approximated by two indirect ways. First, metal washers weighing $30 \mathrm{~g}$ each were placed on stream bottoms to determine rate of washout. Eight washers were placed $30 \mathrm{~cm}$ apart at two locations for each stream. Distances moved and whether washers turned over an odd number of times (each side was painted with a different color) were recorded from the dry season of 1977 to the wet season of 1977. Second, substrata of particle sizes ranging from 1.2 to $15 \mathrm{~cm}$ were sampled from all microsites (except at station 5 in the Sura). Particles from 0.074 to $12 \mathrm{~mm}$ were sampled from all stations in the Sura and from stations 7 through 10 in the Sabalo. The sampler was $13 \mathrm{~cm}$ by $13 \mathrm{~cm}$ with a height of $10 \mathrm{~cm}$. The sides and cone flowing behind the sampler were constructed of Tygon ${ }^{\circledR}$ nylon, mesh size $351 \mu \mathrm{m}$. A small glass jar at the apex of the cone entrapped very fine particles. Large rubble from within the enclosure was picked out visually using a snorkel and a face mask. The remaining material was churned to a depth of 5 $\mathrm{cm}$ and loosened substrata floated into the mesh bag. All material was wet-sieved and separated into the following size categories with soil sieves: $12-9 \mathrm{~mm}, 9$ $4.76 \mathrm{~mm}, 4.76-2 \mathrm{~mm}, 2-0.841 \mathrm{~mm}, 0.841-0.420 \mathrm{~mm}$, $0.420-0.149 \mathrm{~mm}$, and $0.149-0.074 \mathrm{~mm}$. These finer particles were processed by oven drying at $60^{\circ} \mathrm{C}$ for $2 \mathrm{~d}$ and then weighed to the nearest $0.001 \mathrm{~g}$ on a Mettler H30 balance. Particles $>12 \mathrm{~mm}$ were individually weighed, measured for length, and qualitatively coded for presence of periphyton, color, and surface texture.

Animal sampling began July 1975 and ended August 1977. Ten handscreen samples were taken at each of 10 stations in each stream; 3 at each side microsite and 4 at the center microsite for a total of 10 samples per station. Sampling dates included a record low rainfall month (July 1975), a record high rainfall month (July 1976) and a normal wet season (1977). Changes in seasonal abundances are discussed elsewhere (Stout 1978). For purposes of this paper, animal abundance data were averaged over the entire time, eliminating time as a variable.

Numbers of nymphs and adults of each species were treated separately for linear regression analyses. Nymphal and adult stages were treated separately for two-way analyses of variance designed to test possible 
TABle 2. Comparison of microsite fine particle mass proportions for seven size classes between the Sura and Sabalo (2tailed Mann-Whitney $U$ test).

\begin{tabular}{|c|c|c|c|c|c|c|c|}
\hline \multirow[b]{2}{*}{ Sampling locations } & \multicolumn{7}{|c|}{ Substrata categories $(\mathrm{mm})$} \\
\hline & $\begin{array}{l}0.074- \\
0.149\end{array}$ & $\begin{array}{c}0.149 \\
0.420\end{array}$ & $\begin{array}{c}0.420- \\
0.841\end{array}$ & $\begin{array}{c}0.841- \\
2.000\end{array}$ & $2.0-4.76$ & $4.76-9.00$ & $9.0-12.0$ \\
\hline \multicolumn{8}{|c|}{$U$ values } \\
\hline $\begin{array}{l}\text { Sura, Stations } 1-7 \\
\quad(n=21)\end{array}$ & \multirow{2}{*}{$17 * * *$} & \multirow{2}{*}{$47^{* * *}$} & \multirow{2}{*}{$53 * * *$} & \multirow[b]{2}{*}{$79 * *$} & \multirow[b]{2}{*}{$121.5^{\mathrm{NS}}$} & \multirow[b]{2}{*}{$48 * * *$} & \multirow[b]{2}{*}{$72^{* *}$} \\
\hline $\begin{array}{l}\text { Sabalo, Stations } 6-10 \\
\quad(n=15)\end{array}$ & & & & & & & \\
\hline \multicolumn{8}{|c|}{ Percent of total mass } \\
\hline Sura & 2.3 & 5.6 & 9.0 & 11.5 & 20.5 & 22.9 & 28.0 \\
\hline Sabalo & 0.2 & 1.5 & 4.2 & 8.0 & 16.5 & 30.3 & 38.7 \\
\hline
\end{tabular}

effects of station differences, species differences, and interactions between station and species for each stream. The three microsites for each station were treated as replicates for analysis of variance.

\section{RESULTS}

Limnocoris insularis is significantly more abundant in the Sura, which backfloods, than in the Sabalo (adults: $P<.001$; nymphs: $P<.001$ ). Although nymphs of Cryphocricos latus were more common in the Sura $(P<.01)$ adults appear to be equally abundant in the two streams (Table 1; Figs. 1 and 2). Abundances of nymphs and adults of both species do not differ in the downstream vs. upstream stations in the
Sura, but there were significant differences in the downstream vs. upstream stations of the Sabalo (Table 1; Figs. 1 and 2). Upstream in the Sabalo, numbers of both stages of $L$. insularis decrease; however, numbers of both stages of $C$. latus increase upstream. It was hypothesized that these differences could reflect the fact that spates do not affect substrata nearly as much near the mouth as upstream in the Sabalo. First, near station 4, flood waters are partially diverted, flowing directly into the Puerto Viejo; second, water near the stream's mouth is slowed down by the Puerto Viejo, allowing finer sediments to settle out. There are significantly fewer rocks $1.2-5 \mathrm{~cm}$ across at the downstream sites than at the upstream sites (Table 3), in-

TABle 3. Physical differences for microsites in the Sura and Sabalo.

\begin{tabular}{|c|c|c|c|c|c|c|c|c|}
\hline \multirow[b]{2}{*}{$\begin{array}{c}\text { Stream and } \\
\text { stations }\end{array}$} & \multicolumn{8}{|c|}{ Variables } \\
\hline & $\begin{array}{l}\text { Velocity } \\
(\mathrm{cm} / \mathrm{s})\end{array}$ & $\begin{array}{l}\text { Height } \\
\text { of } \\
\text { stream } \\
(\mathrm{cm})\end{array}$ & $\begin{array}{l}\text { Number } \\
\text { of small } \\
\text { rocks } \\
(1.2- \\
3.4 \mathrm{~cm})\end{array}$ & $\begin{array}{c}\text { Number } \\
\text { of medium } \\
\text { rocks } \\
(3.5- \\
4.9 \mathrm{~cm})\end{array}$ & $\begin{array}{l}\text { Number } \\
\text { of large } \\
\text { rocks } \\
(>5 \mathrm{~cm})\end{array}$ & $\begin{array}{c}\text { Number } \\
\text { of black } \\
\text { rocks } \dagger\end{array}$ & $\begin{array}{c}\text { Number } \\
\text { of rocks } \\
\text { without } \\
\text { periphyton }\end{array}$ & $\begin{array}{c}\text { Number } \\
\text { of smooth } \\
\text { rocks } \dagger\end{array}$ \\
\hline \multicolumn{9}{|l|}{ Sura (1-6) } \\
\hline $\bar{x}$ & 49.5 & 45.8 & 32.9 & 5.0 & 2.7 & 20.5 & 3.5 & 3.4 \\
\hline \multicolumn{9}{|l|}{ Sabalo (1-6) } \\
\hline $\begin{array}{l}\bar{x} \\
t_{(34)}\end{array}$ & $\begin{array}{l}46.1 \\
0.41\end{array}$ & $\begin{array}{l}22.3 \\
6.51^{* * * *}\end{array}$ & $\begin{array}{l}48.3 \\
-2.33^{*}\end{array}$ & $\begin{array}{l}9.7 \\
-2.82^{* *}\end{array}$ & $\begin{array}{c}4.6 \\
-2.68^{*}\end{array}$ & $\begin{array}{l}6.6 \\
3.97 * * *\end{array}$ & $\begin{array}{l}16.2 \\
-5.53^{* * *}\end{array}$ & $\begin{array}{l}12.3 \\
-3.70^{* * *}\end{array}$ \\
\hline \multicolumn{9}{|l|}{ Sura $(1-3)$} \\
\hline $\bar{x}$ & 48.9 & 41.4 & 44.1 & 5.9 & 2.9 & 26.3 & 4.8 & 2.4 \\
\hline \multicolumn{9}{|l|}{ Sura $(5-7)$} \\
\hline $\begin{array}{l}\bar{x} \\
t_{(16)}\end{array}$ & $\begin{array}{c}56.3 \\
-0.60\end{array}$ & $\begin{array}{c}42.8 \\
-0.45\end{array}$ & $\begin{array}{l}29.1 \\
1.67\end{array}$ & $\begin{array}{l}4.7 \\
0.49\end{array}$ & $\begin{array}{c}3.2 \\
-0.22\end{array}$ & $\begin{array}{c}17.4 \\
1.18\end{array}$ & $\begin{array}{l}2.6 \\
0.92\end{array}$ & $\begin{array}{c}4.8 \\
-0.78\end{array}$ \\
\hline \multicolumn{9}{|l|}{ Sabalo (1-4) } \\
\hline$\vec{x}$ & 49.0 & 18.3 & 35.9 & 6.3 & 3.2 & 10.6 & 9.6 & 5.8 \\
\hline \multicolumn{9}{|l|}{ Sabalo $(7-10)$} \\
\hline $\begin{array}{l}\bar{x} \\
t_{(22)}\end{array}$ & $\begin{array}{c}48.2 \\
0.08\end{array}$ & $\begin{array}{c}24.4 \\
-1.45\end{array}$ & $\begin{array}{l}52.2 \\
-2.36 *\end{array}$ & $\begin{array}{l}11.3 \\
-3.12 * *\end{array}$ & $\begin{array}{l}5.5 \\
-2.10^{*}\end{array}$ & $\begin{array}{l}4.2 \\
4.12 * *\end{array}$ & $\begin{array}{l}19.6 \\
-2.70^{*}\end{array}$ & $\begin{array}{l}15.6 \\
-2.69^{*}\end{array}$ \\
\hline
\end{tabular}


dicating a slower flow rate during spates there. Correlations between animal abundances and substrata were done and appear later.

\section{Physical differences between stream types}

Because flooding velocities could determine washouts of insects as well as substrates, these were compared in the two streams by measuring distances metal washers moved in the two streams. Washers were lost from both the upstream and downstream sites in the Sabalo after $4 \mathrm{mo}$; yet most of the washers remained in the Sura (100\% for the upstream site and $68 \%$ for the downstream site). The maximum velocity recorded at the downstream site in the Sura was $120 \mathrm{~cm} / \mathrm{s}$; thus water velocities in the Sabalo during spates must greatly exceed $120 \mathrm{~cm} / \mathrm{s}$ because all the washers were lost.

There are also significant differences in particle sizes of substrata between the two streams. The proportion of finer particles, ranging from very fine to coarse sand (three smallest substrata categories in Table 2), is significantly greater in the Sura than in the Sabalo. On the other hand, pebbles (size categories after Cummins and Lauff 1969) ranging from 4.76 to $12 \mathrm{~mm}$ in diameter are significantly more common in the upstream stations in the Sabalo than in the Sura (Table 2). Frequencies of larger particles $1.2 \mathrm{~cm}$ to 3.4 $\mathrm{cm}, 3.5 \mathrm{~cm}$ to $4.9 \mathrm{~cm}$, and cobbles $>5 \mathrm{~cm}$ are also significantly higher at the upper stations of the Sabalo than in the Sura. Spates cause larger rocks to settle out in the upper reaches of the Sabalo, while at the same time they wash out the finer particles. Because the Sura never attains velocities characteristic of the Sabalo during floods, large rocks do not move in the stream, nor do the finer sediments wash out. In fact, during periods of backflooding, fine particles settle out when flow ceases. Some of these fine particles are later washed downstream again when the Sura re-establishes its normal flow pattern.

Associated with differences in maximum velocities between the two streams are qualitative differences in the substrata particles $>12 \mathrm{~mm}$ in diameter. In the Sabalo significantly more are smooth and without periphyton, reflecting the scouring of these rocks during spates, which can occur anywhere from 5 to 15 times during a single wet season.

\section{Relationships between animal abundances and physical factors}

A. Sura Stream.-There are no overall station effects for adults of either species in the Sura (Table 4); i.e., adults show nonsignificant changes with respect to stream site location. However, there are highly significant species effects $(P<.01)$. There is a slight $(P=.08)$ interaction between station and adults of the two species in the Sura; Fig. 2 shows that adults of $L$. insularis seem to prefer some stations more than others, whereas adults of $C$. latus show a more even dis-

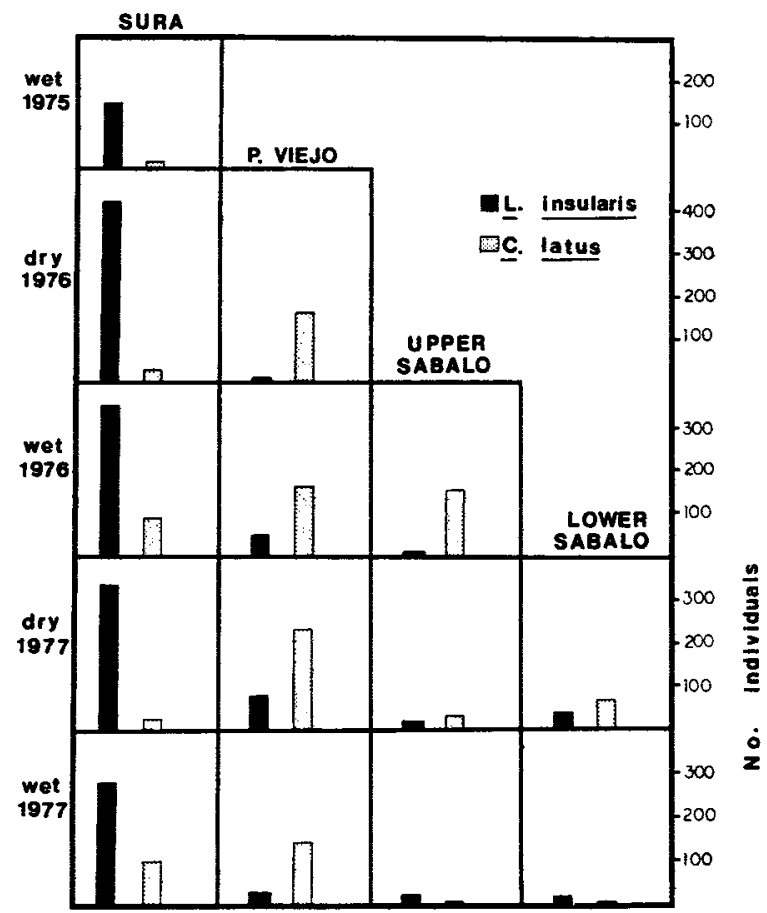

FIG. 1. Numbers of individuals of $L$. insularis and $C$. latus in the Sura and Puerto Viejo, and upstream and downstream sections of the Sabalo.

tribution from station to station. Abundances of adults of the two species at stations 1 through 6 are not tied to each other $\left(r^{2}=.08\right.$; slope of regression line not significant).

Nymphs of $L$. insularis are more common than nymphs of $C$. latus (Fig. 2). There are also highly significant station effects; i.e., nymphs of each species show a significant change in numbers with respect to stream site location $(P<.001)$. Finally, a highly significant negative relationship exists between nymphs of the two species among stations $(P<.001)$. At stations where nymphs of $L$. insularis are most abundant (stations $1,2,5,8$, and 10 ) nymphs of $C$. latus are least abundant (see Fig. 2).

Table 5 shows linear regression values for relationships between physical factors and animal abundances. Velocity plays an important role in the ecological separation of both stages of both species, except for adults of $L$. insularis, which show no consistent pattern relative to velocity (Fig. 3). Abundances of nymphs of that species are negatively related to increasing stream velocities. There appears to be a threshold rather than linear effect. At velocities exceeding $75 \mathrm{~cm} / \mathrm{s}$ nymphal abundances go down very fast (Fig. 3). These animals are found primarily along stream sides having the lowest velocities relative to other microsites within each station. It was noticed that freshly molted instars could not break the water surface and re-enter the stream nearly as fast as hard- 

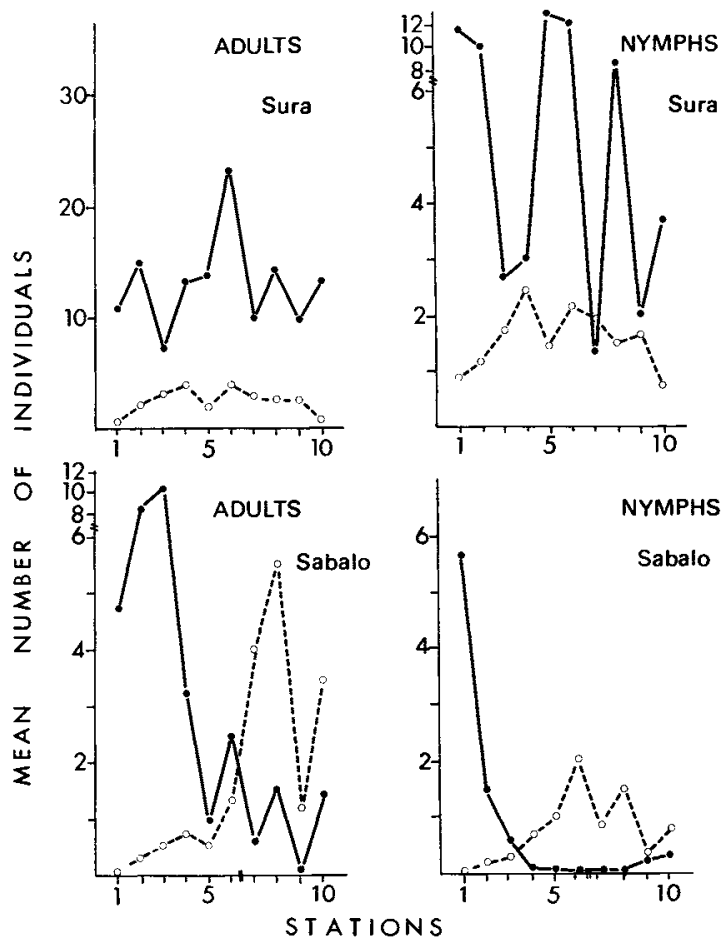

Fig. 2. Abundances of adults and nymphs of $L$. insularis (solid circles) and C. latus (open circles) in the Sura and Sabalo stations.

ened instars. Certainly, sections of streams having high velocities could force newly molted animals downstream a considerable distance if the animals had to go to the surface for any reason.

Both adults and nymphs of $C$. latus are positively related to increasing velocities (Fig. 3). More of the variance in adult and nymphal abundances for this species among the microsites can be accounted for by velocity (adults, $r^{2}=.39$; nymphs, $r^{2}=.33$ ) than for adults or nymphs of $L$. insularis (adults $=.05$, nymphs $=.21$ ), Table 5 . Abundances of both adults and nymphs of $C$. latus are highest at stations 4 and 6 where the microsite velocities are uniformly high.

Nymphs of $L$. insularis showed a significant linear relationship to the abundance of fine granules ranging
L. insularis, ADULTS

L. insularis, NYMPHS

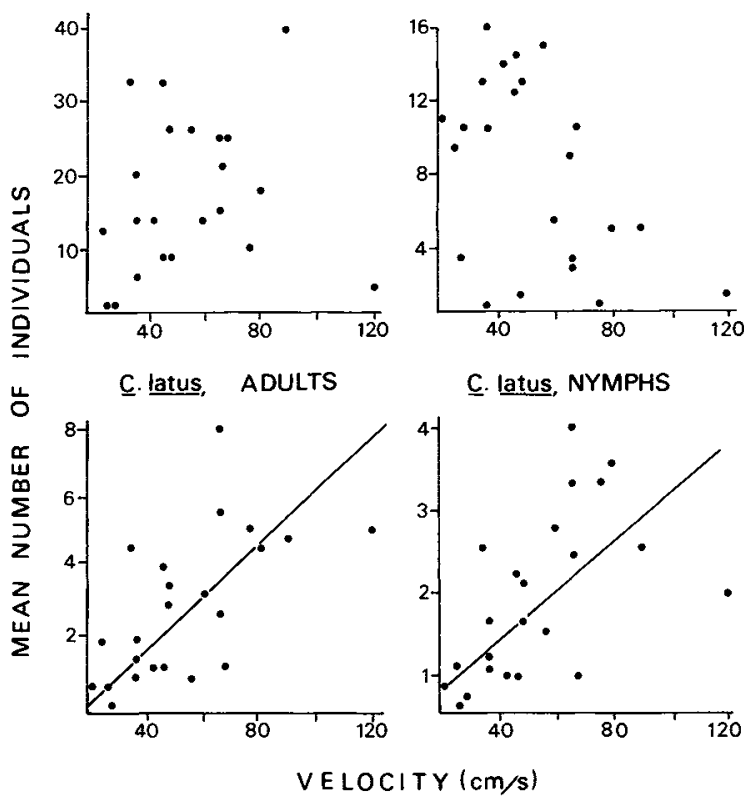

FIG. 3. Relationship of stages and species of naucorids to current velocity in the Sura.

from fine to coarse sand. The slope of the regression line is significant at the $P<.05$ level (Fig. 4). Again, as for velocity, not much of the variance in abundances of nymphs of this species can be accounted for on the basis of fine to coarse sand alone $\left(r^{2}=.20\right)$.

Masses of 4.76-12 mm diameter pebbles relative to the masses of all other small particles $(<4.76 \mathrm{~mm})$ accounted for most of the variance in abundance of adults and nymphs of $C$. latus in the Sura $\left(r^{2}=.97\right.$ and .84 , respectively). The overall velocity regime controls particle distribution in stream bottoms. Rather than measuring velocities over time, a time-consuming undertaking, fractionation of substrata into various size components appears to be a better method for determining relationships between abundances of these animals and physical factors (Fig. 5).

Abundances for nymphs of $L$. insularis are nega-

TABLE 4. Analyses of variance of adult and nymphal abundances for $L$. insularis and $C$. latus in the Sura. (Means and standard deviations for stations come from average number of animals per microsite with $n=3$ microsites per station.)

\begin{tabular}{|c|c|c|c|c|c|c|}
\hline \multirow[b]{2}{*}{ Source } & \multicolumn{3}{|c|}{ Adults } & \multicolumn{3}{|c|}{ Nymphs } \\
\hline & ss & df & $F$ value & ss & df & $F$ value \\
\hline Main effects of station & 279.67 & 5 & 2.31 & 163.46 & 5 & $16.84^{* * *}$ \\
\hline Main effects of species & 954.22 & 1 & $62.26^{* *}$ & 228.74 & 1 & $92.25^{* * *}$ \\
\hline $\begin{array}{l}\text { Interaction of } \\
\text { station and species }\end{array}$ & 199.17 & 5 & $2.60 \dagger$ & 205.01 & 5 & $16.53 * * *$ \\
\hline Error & 183.92 & 12 & & 29.76 & 12 & \\
\hline
\end{tabular}

$P<.10=\uparrow ; P<.01=* * ; P<.001=* * *$. 


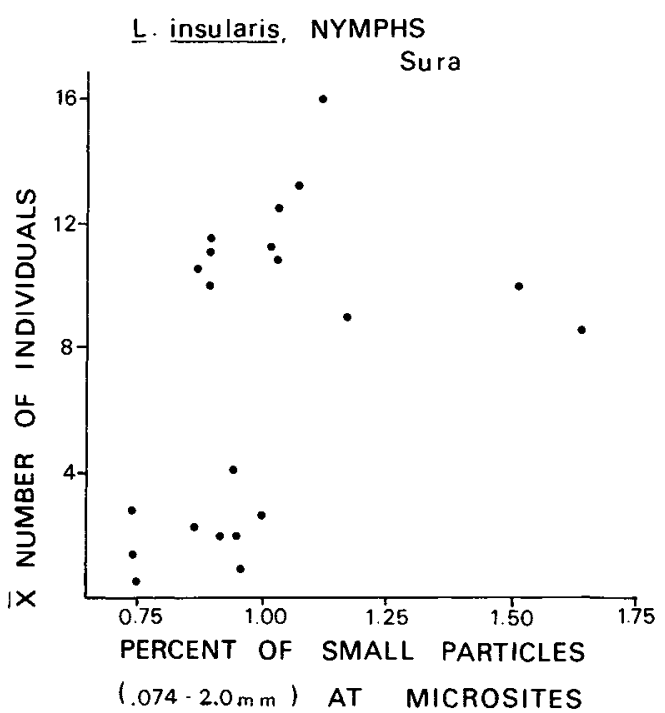

FIG. 4. Relationship of nymphs of $L$. insularis to the percentage of small particles $(0.074-2.00 \mathrm{~mm}$ in diameter) at microsites in the Sura.

tively related to increasing proportions of these particles at the microsites. Although the slope of the regression line is significant $(P=.05)$ only $18 \%$ of the variance in abundances of these nymphs can be accounted for on the basis of this variable.

The last physical variable showing a linear relationship with animal abundances in the Sura is the number of rocks $>3.5 \mathrm{~cm}$ in diameter. Both adults and nymphs of $C$. latus show a positive linear relationship with respect to this variable, although little variance for either stage can be accounted for on the basis of rock sizes alone (Table 5).

B. Sabalo Stream.-In the Sabalo there are significant effects of station and of adult abundances between the two species for all stations (Table 6). Also, interactions between stations and species are highly significant $(P<.001)$. Abundances of adults of $C$. latus increase from downstream to upstream stations (Fig. 2), whereas abundances of adults of $L$. insularis decrease as one moves upstream from the mouth of the Sabalo. There are no station effects for nymphal abundances for the combined downstream and upstream stations in the Sabalo. Neither are there effects due to species abundances. A different pattern emerges when nymphal abundances at the downstream and upstream stations are analyzed separately. In the six downstream stations there is a significant effect due to the interaction between species and station (Table 7A). In the four upstream stations, there is a significant effect due to station, and a significant effect due to species, but there is no significance due to the interaction between species and station (Table 7B). This latter result is due to the fact that nymphs of $L$. insularis numerically dominate the three down-

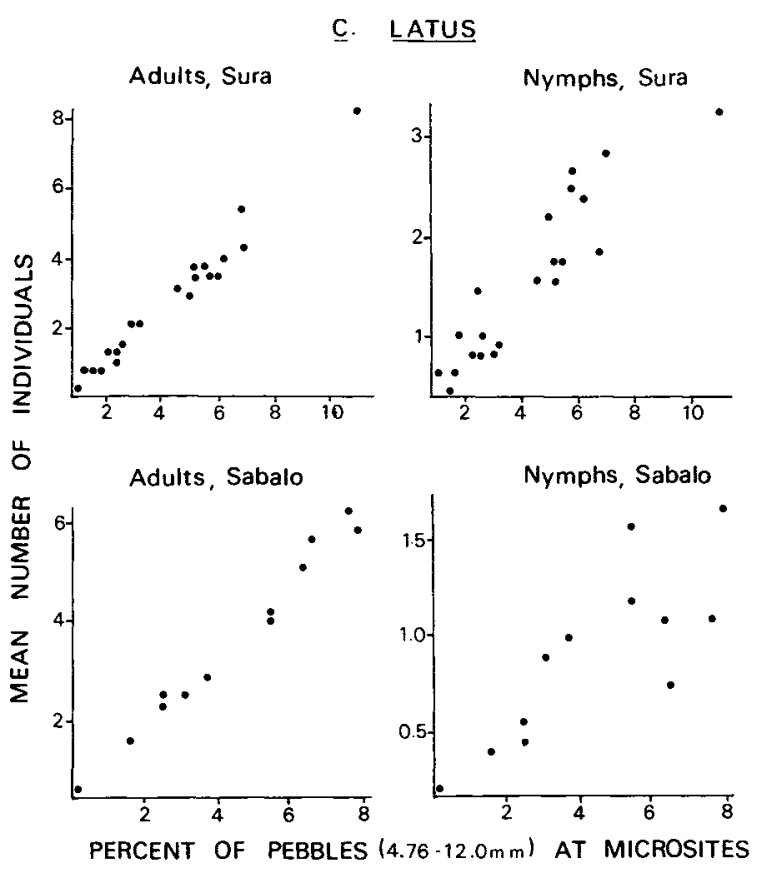

Fig. 5. Relationship of nymphs and adults of C. latus to the percentage of pebbles ranging from 4.76 to $12 \mathrm{~mm}$ in diameter at microsites in the Sura and Sabalo.

stream stations, whereas nymphs of $C$. latus are relatively common in the upstream stations. In those upstream stations, nymphs of $L$. insularis are very rare (Fig. 2).

Table 8 presents results of linear regressions of stages and species of naucorids with respect to physical variables. In contrast to the Sura, for the Sabalo there was no correlation between velocity and animal abundances, probably owing to the fact that maximum velocities could not be taken in this stream during

TABLE 5. Relationship of abundances of animals to physical factors in the Sura. LA = Limnocoris insularis adults; LN $=$ Limnocoris insularis nymphs; $\mathrm{CA}=$ Cryphocricos latus adults; $\mathrm{CN}=$ Cryphocricos latus nymphs.

\begin{tabular}{|c|c|c|c|c|c|}
\hline Variable & $\begin{array}{l}\text { Spe- } \\
\text { cies }\end{array}$ & $n$ & Slope & $\begin{array}{c}\text { Signifi- } \\
\text { cance } \\
\text { level } \\
(\alpha)\end{array}$ & $r^{2}$ \\
\hline Velocity $(\mathrm{cm} / \mathrm{s})$ & $\begin{array}{l}\text { LA } \\
\text { LN } \\
\text { CA } \\
\text { CN }\end{array}$ & $\begin{array}{l}21 \\
21 \\
21 \\
21\end{array}$ & $\begin{array}{r}0.091 \\
-0.097 \\
0.052 \\
0.024\end{array}$ & $\begin{array}{l}.315 \\
.027 \\
.001 \\
.004\end{array}$ & $\begin{array}{l}.05 \\
.21 \\
.39 \\
.33\end{array}$ \\
\hline $\begin{array}{l}\text { Sand, } 0.074- \\
\quad 2.0 \mathrm{~mm} \text { in diameter }\end{array}$ & $\mathrm{LN}$ & 21 & 0.804 & .041 & .20 \\
\hline $\begin{array}{l}\text { Pebbles, } 4.76- \\
12 \mathrm{~mm} \text { in diameter }\end{array}$ & $\begin{array}{l}\mathbf{L N} \\
\mathrm{CA} \\
\mathrm{CN}\end{array}$ & $\begin{array}{l}21 \\
21 \\
21\end{array}$ & $\begin{array}{r}-0.772 \\
0.703 \\
0.297\end{array}$ & $\begin{array}{l}.056 \\
.000 \\
.000\end{array}$ & $\begin{array}{l}.18 \\
.97 \\
.84\end{array}$ \\
\hline $\begin{array}{l}\text { Rocks }>3.5 \mathrm{~cm} \text { in } \\
\text { length }\end{array}$ & $\begin{array}{l}\mathrm{CA} \\
\mathrm{CN}\end{array}$ & $\begin{array}{l}21 \\
21\end{array}$ & $\begin{array}{l}0.115 \\
0.064\end{array}$ & $\begin{array}{l}.066 \\
.041\end{array}$ & $\begin{array}{l}.15 \\
.18\end{array}$ \\
\hline
\end{tabular}




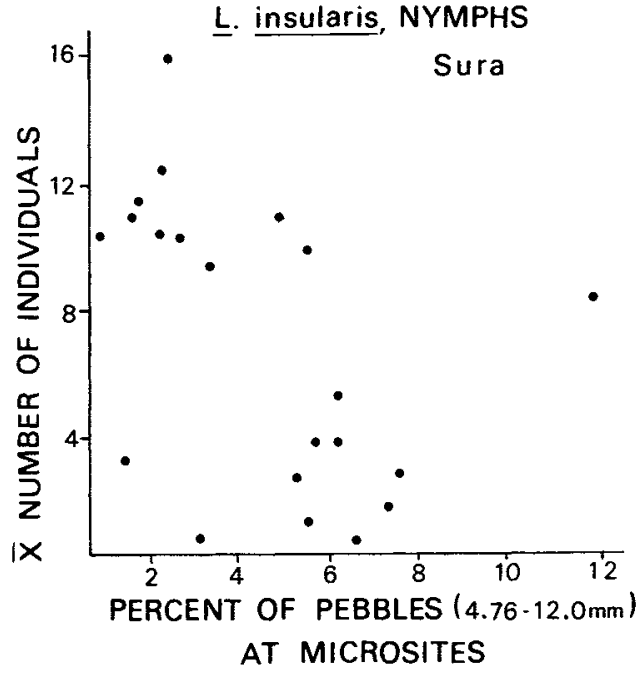

Fig. 6. Relationship of nymphs of $L$. insularis to the percentage of substrata ranging in size from 4.76 to $12 \mathrm{~mm}$ in diameter at microsites in the Sura.

floods. However, substrata particle sizes, which reflect maximum velocities, show relationships with animal abundances. Abundances of adults and nymphs of $C$. latus show a positive linear relationship with microsites containing proportionately more pebbles $4.76-12 \mathrm{~mm}$ in diameter $\left(r^{2}=.98\right.$ for adults; $r^{2}=.65$ for nymphs; see Fig. 5). No relationship was found for either adults or nymphs of $L$. insularis. Abundances are low at the upstream stations, which probably accounts for the lack of a relationship between abundances of this species and the substrate type. If a negative relationship were to be found with respect to nymphs of $L$. insularis (as was the case in the Sura) it would have been at the downstream stations where nymphs are the most plentiful. However, data for the finer particles from 4.76 to $12 \mathrm{~mm}$ are lacking for the downstream sites.

\section{Discussion}

When backflooding occurs, the Sura becomes a lake, yet there are no significant shifts in animal abundances over time (Stout 1979). In contrast to the Sura, the Sabalo shows significant changes in animal abundances after spates; i.e., flooding patterns affect several variables: (1) substrata character, (2) velocity, and (3) disturbance of the biotic community. Naucorids respond to those variables by (1) selecting certain habitats; (2) behaviorally responding to the velocity; and (3) having differential resiliencies to disturbance, depending on their movement and reproductive capabilities (Stout 1979). Laboratory experiments also support these findings ( $R$. J. Stout, personal observation).

The basic pattern of distribution is explained by the difference between the flooding characteristics of the two streams. The disparate flow patterns cause substrata to deposit according to size and mass. Extremes in flow also cause biotic drifting. One animal, C. latus, drifts according to the principle of biotic drifting, but the other animal, $L$. insularis, does not. It migrates upstream over its entire life cycle. Thus there exists a complex web of causality. A physical factor (spating or backflooding) determines an environmental pattern, which is the substrate character. The two species respond behaviorally to that environmental pattern. But it is the same physical factor, i.e., whether the stream is spated or backflooded, that causes the animals to be relocated, sometimes drastically. Finally, the animal's behavior determines the ultimate population pattern; either they fly upstream or crawl upstream to preferred habitats (Stout 1979).

Both species prefer riffles. Limnocoris insularis has certain riffle site preferences in the Sura, and these bugs are even more abundant there in the dry season (Stout 1978). In the Sura both species tend to live in riffles irrespective of distance from the stream's mouth. However, in the Sabalo the two species show riffle preferences that are related to distance from the stream's mouth because of the influence of the Puerto Viejo River on the flooding phenomenon in the Sabalo. Individuals of $L$. insularis are more frequent near the mouth than upstream in the Sabalo. Nymphs virtually disappear upstream, except at some sheltered stream edge sites, but adults are more common there. Nymphs and adults of that species move upstream along the bottom (Stout 1979) and so, after spates, they can recolonize scoured-out areas either by coming in from the Puerto Viejo (where they are common

TABLE 6. Analyses of variance of abundance of adults and nymphs for $L$. insularis and $C$. latus in the Sabalo. (Means and standard deviations for stations come from average number of animals per microsite with $n=3$ microsites per station.)

\begin{tabular}{|c|c|c|c|c|c|c|}
\hline \multirow[b]{2}{*}{ Source } & \multicolumn{3}{|c|}{ Adults, stations 1 through 10, Sabalo } & \multicolumn{3}{|c|}{ Nymphs, stations 1 through 10 , Sabalo } \\
\hline & ss & df & $F$ value & ss & df & $F$ value \\
\hline $\begin{array}{l}\text { Main effects of station } \\
\text { Main effects of species } \\
\text { Interaction of station and species }\end{array}$ & $\begin{array}{r}124.2 \\
40.6 \\
302.5\end{array}$ & $\begin{array}{l}9 \\
1 \\
9\end{array}$ & $\begin{array}{r}6.17^{* * *} \\
23.58^{* * *} \\
19.54^{* * *}\end{array}$ & $\begin{array}{r}28.9 \\
0.2 \\
60.1\end{array}$ & $\begin{array}{l}9 \\
1 \\
9\end{array}$ & $\begin{array}{l}1.92 \\
0.13 \\
4.25^{* *}\end{array}$ \\
\hline Error & 34.4 & 20 & & 31.5 & 20 & \\
\hline
\end{tabular}

$P<.01={ }^{* *} ; P<.001=* * *$. 
TABLE 7. A: Analyses of variance of abundances of adults and nymphs for $L$. insularis and $C$. latus in the Sabalo, stations 1 through 6.

\begin{tabular}{|c|c|c|c|c|c|c|}
\hline \multirow[b]{2}{*}{ Source } & \multicolumn{3}{|c|}{ Adults } & \multicolumn{3}{|c|}{ Nymphs } \\
\hline & ss & df & $F$ value & ss & df & $F$ value \\
\hline $\begin{array}{l}\text { Main effects of stations } \\
\text { Main effects of species } \\
\text { Interaction of station and species }\end{array}$ & $\begin{array}{r}93.76 \\
181.32 \\
112.36\end{array}$ & $\begin{array}{l}5 \\
1 \\
5\end{array}$ & $\begin{array}{c}7.07^{* *} \\
29.46^{* * *} \\
11.46^{* * *}\end{array}$ & $\begin{array}{r}25.65 \\
3.20 \\
53.44\end{array}$ & $\begin{array}{l}5 \\
1 \\
5\end{array}$ & $\begin{array}{l}1.87 \\
1.25 \\
4.18^{*}\end{array}$ \\
\hline Error & 23.53 & 12 & & 30.67 & 12 & \\
\hline
\end{tabular}

B: Analyses of variance of abundances of adults and nymphs for L. insularis and C. latus in the Sabalo, stations 7 through 10.

\begin{tabular}{lccccccc}
\hline & \multicolumn{3}{c}{ Adults } & & \multicolumn{3}{c}{ Nymphs } \\
\cline { 2 - 6 } \multicolumn{1}{c}{ Source } & ss & df & $F$ value & & ss & df & $F$ value \\
\hline Main effects of stations & 25.87 & 3 & $5.77^{*}$ & & 0.87 & 3 & $5.03^{*}$ \\
Main effects of species & 41.23 & 1 & $30.35^{* *}$ & & 2.20 & 1 & $22.67^{* * *}$ \\
Interaction of station and species & 8.18 & 3 & 2.01 & & 1.46 & 3 & $5.00^{* *}$ \\
Error & 10.87 & 8 & & & 0.78 & 8 & \\
\hline
\end{tabular}

$P<.05={ }^{*} ; P<.01={ }^{* *} ; P<.001=* * *$.

along the river's edge) or by regaining "lost ground" within the stream itself by simply crawling upstream.

The nymphal stage of $L$. insularis is crucial to the recolonization cycle. They are more abundant in microsites containing relatively large amounts of fine to coarse sand. The Sabalo in its upper reaches contains habitats rich in smooth, large rocks but poor in finer substrata. Nymphs do not do well there, and adults are more abundant than the nymphs. Adults are, however, less abundant at microsites containing many large rocks. The number of large rocks per se, which is dependent upon the flooding, is probably not the variable crucial to the low abundances of these animals, but, rather, the maximum velocities which secondarily cause these large rocks to be deposited. A spate that occurred upstream in October of 1976 virtually demolished populations of both species at the upstream sites. With time, adults of $L$. insularis became more abundant but nymphal numbers always remained low. Adults can recolonize by moving upstream, but nymphs are more sensitive to high velocities and to the paucity of finer sediments, resulting in a disproportionate loss of that stage.

There appears to be no crucial life history breakpoint for $C$. latus. Both nymphs and adults are positively related to increasing velocities and to larger particles on stream bottoms. Both stages are equally abundant at the various microsites over time. Thus, if one finds adults of $C$. latus one will also likely encounter nymphs during the reproductive season. Both stages are more abundant upstream. It is in the upper stations of the Sabalo that their abundances are positively correlated with large substrata. They do not crawl upstream but remain semistationary on sides of rocks, waiting for prey. Their ability to remain there during floods is related to velocity. Once a rock overturns, these animals can enter the drift. If this happens (unlike the behavioral response of individuals of $L$. insularis, which swim to the bottom again), C. latus passively floats and is swept many metres downstream. The unusual spate that occurred in October of 1976 severely reduced populations of both species. The populations did not recover (at least by March of 1980) to their original abundances. Because $C$. latus does not crawl upstream, it can only recolonize areas severely affected by spates by flying upstream (Stout 1979). Although most adults are brachypterous, some are macropterous, and have the ability to fly before laying eggs. But that mode of recolonization apparently takes a rather long time to compensate for losses following severe spates.

Although both species occur in the streams, only $C$. latus reproduces equally well in both. Nymphal abun-

TABLE 8. Relationship of abundances of animals to physical factors in the Sabalo. LA = Limnocoris insularis adults; $\mathbf{L N}=L$. insularis nymphs; $\mathbf{L}$ total $=L$. insularis adults and nymphs; $\mathrm{CA}=$ Cryphocricos latus adults; $\mathrm{CN}=C$. latus nymphs; $\mathrm{C}$ total $=C$. latus adults and nymphs.

\begin{tabular}{|c|c|c|c|c|c|}
\hline Variable & Species & $n$ & Slope & $\begin{array}{l}\text { Signifi- } \\
\text { cance } \\
\text { level }(\alpha)\end{array}$ & $r^{2}$ \\
\hline $\begin{array}{l}\text { Pebbles } 4.76-12 \\
\mathrm{~mm} \text { in diameter }\end{array}$ & $\begin{array}{l}\mathrm{CA} \\
\mathrm{CN}\end{array}$ & $\begin{array}{l}12 \\
12\end{array}$ & $\begin{array}{l}0.852 \\
0.148\end{array}$ & $\begin{array}{r}\ll .001 \\
.002\end{array}$ & $\begin{array}{l}.98 \\
.65\end{array}$ \\
\hline $\begin{array}{c}\text { Rocks }>3.5 \mathrm{~cm} \\
\text { in diameter }\end{array}$ & $\mathrm{CA}$ & 30 & 0.234 & $\ll .001$ & .38 \\
\hline $\begin{array}{r}\text { Rocks }>5 \mathrm{~cm} \\
\text { in diameter }\end{array}$ & $\begin{array}{l}\text { LA } \\
\text { L total } \\
\text { C total }\end{array}$ & $\begin{array}{l}30 \\
30 \\
30\end{array}$ & $\begin{array}{r}-0.732 \\
-0.829 \\
0.530\end{array}$ & $\begin{array}{l}.012 \\
.014 \\
.003\end{array}$ & $\begin{array}{l}.21 \\
.20 \\
.28\end{array}$ \\
\hline
\end{tabular}


dances of $L$. insularis are severely reduced in the Sabalo because fine sand habitats are rare upstream of its mouth. Even though adults can recolonize upstream areas, they cannot reproduce themselves as well in streams that spate. Cryphocricos latus can reproduce in both streams, even under conditions of high velocities. Only in periods of intense floods are these animals washed downstream (Stout 1979). The population of this species fluctuates more in the Sabalo than in the Sura for two reasons. First, they can be washed out of the Sabalo, and second, they can recolonize only via the winged form during a single reproductive season.

Nymphs and adults of both species are abundant in the Sura. Both adults and nymphs of $C$. latus increase in abundance with increasing stream velocities. Further, particle composition of the substrata in stream bottoms in the Sura affects animal abundances. Numbers of $L$. insularis nymphs are negatively related to the abundance of large rocks. Nymph abundances are also directly related to microsites that contain more fine and coarse sand relative to other microsites. No other stage or species shows a significant linear relationship with this variable. Numbers of adults and nymphs of $C$. latus are positively related to large rocks, and not to the absence of $L$. insularis. Interactions between the two species were never observed under field conditions. On the basis of experiments designed to look at possible interactions between the two species and experiments designed to look at responses of the animals to physical variables ( R. J. Stout, personal observation), in conjunction with field data, it appears that physical factors separate the two species more than any behavioral interaction between them.

\section{ACKNOWLEDGMENTS}

This work was supported by a predoctoral fellowship from the Rackham Graduate School at the University of Michigan, an Organization for Tropical Studies Field Grant, and an American Association of University Women Predoctoral Fellowship. I thank Brian Hazlett, Susan S. Kilham, Peter Kilham, Kenneth Cummins, John Witter and Beverly J. Rathcke for their comments on the manuscript. This paper is from a thesis submitted to the Graduate Faculty of The University of Michigan in partial fulfillment of the requirements for the degree of Doctor of Philosophy.

\section{Literature Cited}

Cummins, K. W. 1964. Factors limiting the microdistribution of the caddisflies Pycnopsyche lepida (Hagen) and Pycnopsyche guttifer (Walker) in a Michigan stream (Tricoptera: Limnephilidae). Ecological Monographs 34:271295.

Cummins, K. W., and G. H. Lauff. 1969. The influence of substrate particle size on the microdistribution of stream macrobenthos. Hydrobiologica 34:145-181.

Hynes, H. B. N. 1970. The ecology of running waters. University of Toronto Press, Toronto, Ontario, Canada.

Edington, J. J. 1965. The effect of water flow on populations of net-spinning Trichoptera. Internationale Vereinigung für Theoretische und Angewandte Limnologie, Mitteilungen 13:40-48.

1968. Habitat preferences in net-spinning caddis larvae with special reference to the influence of water velocity. Journal of Animal Ecology 37:675-692.

Egglishaw, H. J. 1969. The distribution of benthic invertebrates on substrata in fast-flowing streams. Journal of Animal Ecology 38:19-33.

Reice, S. R. 1980. The role of substratum in benthic macroinvertebrate microdistribution and litter decomposition in a woodland stream. Ecology 61:580-590.

Stout, R. J. 1978. Migration of the aquatic hemipteran Limnocoris insularis (Naucoridae) in a tropical lowland stream (Costa Rica, Central America). Brenesia 14-15:1-11.

. 1979. The influence of biotic and abiotic factors on two species of stream inhabiting tropical hemiptera (family: Naucoridae). Dissertation. University of Michigan, Ann Arbor, Michigan, USA. 